\section{National Swedish IGBP-PAGES Meeting}

\author{
Lund/Höör, Sweden, 30 September - 3 October, 1999
}

Arranged by the Swedish IGBP \& WCRP committee and co-sponsored by the Royal Swedish Academy of Science and the Swedish Natural Science Research Council.

The overall objectives of 'our' 1999 meeting were the following: (1) identifying ongoing PAGES-related research in Sweden, (2) exploring the interest in participating in the PEP III transect and in IGBP Focus 3 and possible contributions to these two research activities, (3) marine-terrestrial correlations, (4) decreasing the 'misunderstandings' between the palaeo-data and modelling communities.

Altogether 60 scientists (including 10 invited speakers) attended the meeting. Each university / research centre and their Earth Science departments were represented, as well as Archaeology and Ecology. PhD students made up one third of the participants and the proportion of young scientists in general was high.

The meeting was organised into the following sessions each chaired most competently by PhD students:

In Session 1 (PAGES- related research in Sweden: general topics, lectures addressed correlations between marine records and long loess stratigraphies on the Chinese Loess Plateau based on detailed clay mineralogical investigations (Eve Arnold), ${ }^{10} \mathrm{Be}$ dating and correlations between Lake Baikal sediments, ice core and marine records (Ala Aldahan), highly promising attempts at using radioisotopes $\left({ }^{10} \mathrm{Be},{ }^{26} \mathrm{Al},{ }^{36} \mathrm{Cl}\right)$ to date pre-glacial high mountain surfaces (Arjen Stroeven), a summary of Swedish Late Quaternary research in the Arctic and Antarctic and the involvement in the QUEEN Project (Christian Hjort), glacial and environmental history of western Svalbard during the last interglacial/glacial cycle and its relationship to the Barents Sea Ice Sheet (Torbjörn Andersson), a comparison between geomorphological features and models to understand Weichselian ice sheet inception in Fennoscandia and North America (Johan Kleman), boundary conditions for modelling different stages of the Scandinavian ice sheet (Per Holmlund) and a varve record from south-eastern Sweden (Bertil Ringberg). Kurt Lambeck presented a thickness model for the
Late Weichselian Scandinavian ice sheet based on shoreline data and found e.g. that rapid melting must have occurred already before or at around $16 \mathrm{ka}{ }^{14} \mathrm{C} \mathrm{BP}$ and that the eastern part of the ice sheet must have been considerably thinner than previously thought. Frank Oldfield's lecture gave an overview of PAGES and its present and future activities

In session 2 (modelling climate change) Hans Renssen showed model simulations of the European Younger Dryas climate and compared the results with reconstructions based on proxy records, Andrey Ganopolski presented various scenarios of thermohaline circulation in the past and future and Erland Källén discussed the first results of ongoing regional climate model simulations.

Session 3 started with instrumental records (a correlation between Swedish instrumental climate records, Baltic Sea ice extent and the NAO index by Deliang Chen and pressure tendency variations during the past 200 years over Lund by Lars Bärring), which were followed by climate proxy recordts (a 7400-year long tree ring record from northern Sweden by Håkan Grudd), $\delta^{18} \mathrm{O}$ measurements in biogenic silica (Ninis Rosqvist) and a presentation of ISOMAP (Dan Hammarlund).

Session 4 on prehistoric and historical dynamics of land use focussed on a presentation of the new PAGES Focus 3 activiities, HITE (Human Impact on Terrestrial Ecosystems) (Frank Oldfield, Marie-José Gaillard) and LIMPACS (Human Impact on Lake Ecosystems) (Rick Batterbee). Examples of an ongoing study, which aims at quantifying land-use and landcover changes, were reported by MarieJosé Gaillard. The need of high time resoolution in studying human impact was stressed by Björn Berglund, and Paul Sinclair pointed to the importance of an interaction between archaeology and natuural sciences.

Session 5 (rapid changes during the Late Quaternary) was dominated by correlations between marine, ice core and terrestrial records on various time scales. Nalan Koc's and Tine Rasmussen's presentations focussed on temperature, salinity and circulation changes in the North Atlantic during the last interglacial/ glacial cycle and their coupling with

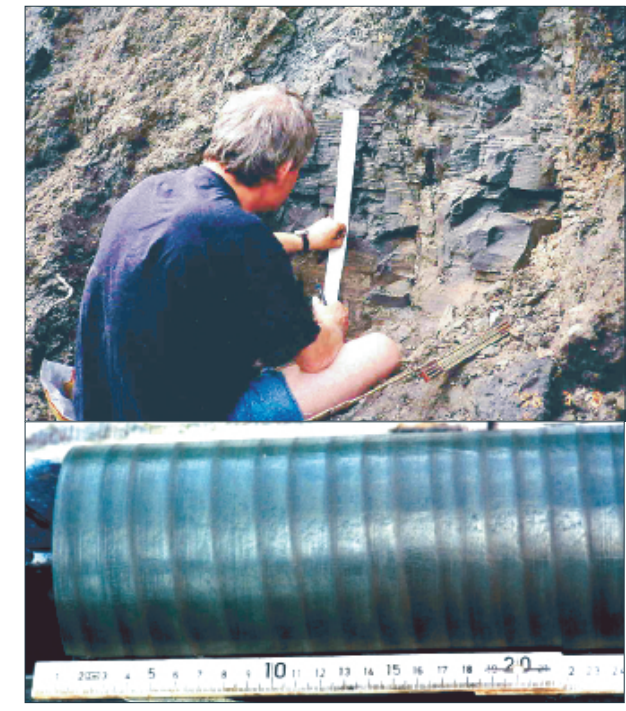

Sweden is home of the first Quaternary time scale, based on De Geer's and Lidén's classic glacial and postglacial varved clays. These beautiful annually laminated sediments can be found all along the Swedish east coast and along the valley of the River Angermanälven. The upper photograph is of Svante Björk sampling a section of postglacial varves, the lower one is of glacial varves from a sediment core. The Swedish record of overlapping varve sequences has provided an almost continuous chronology for the last 14,000 years. For details of ongoing work see:http://www.geol.lu.se/ personal/baw/Swedish_Time_Scale.html

atmospheric variability. Gerard Bond's lecture dealt with North Atlantic millennial-scale climate variability during the Holocene and gave a closer look at how these cycles are expressed and reconstructed in the marine cores. A terrestrial view point on rapid climate changes and their coupling to marine and ice core records was given by Svante Björck. Richard Gyllencreutz presented recently obtained, high-resolution marine cores from the southern Nordic Sea (Leg 3, IMAGES V-CALYPSO. Holocene marine records from the Baltic Sea, which exhibit excellent (partly annual) time resolution, were the object of an investigation presented by Thomas and Elinor Andrén.

Session 6, which dealt with possible Swedish contributions to the PAGESPEP III transect, was introduced by Rick Battarbee, who presented the general rationale and planned activities within PEP III. Stefan Wastegård's example of tephrochronological studies in southern Sweden and on the Faroe Islands clearly show their increasing importance. Speleothems are another archive with highresolution and Karin Holmgren's study in southern Africa revealed their potential for temperature and precipitation 
reconstructions. Ian Snowball's and Lena Barnekow's talk focussed on annually laminated lake sediments from northern Sweden, which have been studied with a variety of different biological, physical and chemical methods.

Fifteen posters gave also an excellent overview of ongoing PhD work, with topics such as glacial lithostratigraphy in northern Russia (Helena Alexandersson, Hanna Lokranz), loess stratigraphy (Susanne Gylesjö), multi-proxy studies of lake sediments (Lena Rubensdotter, Maria Malmström, Camilla Andresen et al., Peter Rosén et al., Lovisa Zillén), quantification of environmental and climatic parameters (Christian Bigler, Anna Broström, Mikkel Sander, Björn Gunnarsson, Hans Linderholm). Furthermore, lake-level reconstructions in Greece (Gunnar Digerfeldt et al.), fish remains and their ecological importance in Swedish late glacial sediments (Leif Jonsson) and a new detailed lake sediment study from the Karelian Isthmus (Dmitry Subetto et al.) were presented.

The discussions in working group session 1 (Marie-José Gaillard) led to the following conclusions:

1. Within global change research, the major challenge for the community of researchers concerned about past human impact is (a) to identify and quantify human-induced land-cover changes and (b) to identify and quantify the effects of land-use/land-cover changes on ecosystems and climate.

2. There is an urgent need to create a national and international network of people interested in these questions and coming from a large number of disciplines, e.g. vegetation and climate modellers, historians, vegetation historians, archaelogists, climate historians, etc.

3. The BIOME-300 activity planned within the HITE program is a good start to approach these questions and to build up a network of scientists.

The major outcome of the discussions was the decision to build up a database of scientists interested in HITE and of potential sites with data relevant to the aims of BIOME-300. Marie-José Gaillard, who was involved in the organisation of the first meeting of BIOME-300 in March this year, hopes to initiate a "HITE- database" and a "HITE home-page" on a national scale after the first meeting.

Working group session 2 (Ian Snowball) dealt mainly with the need of estab- lishing more high-resolution records, i.e. data sets with annual or seasonal resolution to aid in prolonging the instrumental records back in time. Examples of such data sets are the long tree ring records in northern Scandinavia, laminated lake sediments in Fennoscandia and speleothems, which may be calibrated against instrumental data and could thus potentially be used to quantify climatic and environmental parameters. Several projects are already in progress such as e.g. LAMSCAM (see http://wwww.geol.lu.se/ personal/ias/lamscan.html) and it would seem appropriate in the near future to compare all available data sets.

Working group session 3 (Torbjörn Andersson) emphasised the importance of studying records on longer time scales, where e.g. shifts between interglacial and glacial conditions, including rapid natural climate shifts can be studied in detail. Combined efforts, which include different Earth Science disciplines, such as e.g. the QUEEN project can lead to new views on, among others, the ice sheet extent during the Late Glacial Maximum. Furthermore, close-up looks and detailed multidisciplinary investigations of certain interesting time windows will allow deciphering forcing mechanisms behind natural short-term climate shifts. As such, it seems important for PAGES and its future work, not only to concentrate on the recent time periods, where annual resolution is available, but to pay equal attention to our not so distant past.

Common for all three working groups was the large interest in co-operating much more with the modelling community and to combine and test different types of Earth System Models with real data sets.

In the plenary session on the afternoon of the last day, the consensus was that it would be desirable to have these meetings on a regular basis. Points raised during the discussion were:

- The need for data quantification and interactions between data people and Earth System modellers

- Encouraging and promoting the integration/collaboration between archaeologists and Earth Science, i.e. including the human dimension in past climate studies

- The need to investigate phase-lags and responses within individual sites based on multidisciplinary studies
- The importance of anti-correlation between different proxy records

- An increased involvement of junior researchers

Immediate outcomes of the meeting are:

- A second meeting in autumn 2001 in Stockholm, which will be organised by Eve Arnold, Bertil Ringberg, Ninis Rosqvist and Stefan Wastegård (Geology and Physical Geography, Stockholm University).

- Earth System Modelling course in autumn 2001, which will be organised by Eve Arnold (Geology, Stockholm University)

- Initiating a Swedish database of scientists interested in HITE and of a Swedish PEP III / PAGES home page (see above)

The addresses of many scientists, who are involved in PAGES activities within Sweden, are now accessible at http:// www.geol.lu.se/personal/ias/pages/ sweADDRES 1.html.

\section{Barbara Wohlfarth}

Department of Quaternary Geology, Lund University, Sweden

Barbara.Wohlfarth@geol.lu.se

\section{Biörn E. Berglund}

In June 2000 Björn Berglund retired as Director of the Department of Quaternary Geology in Lund, Sweden, a post he held since 1971. During these years the Department evolved into one of the world's leading Quaternary institutes, distinguished for innovative and thorough basic research as well as for benchmark overviews. Björn's contributions have been outstanding. He served on the PAGES SSC in its early years, from 1991-1993. His scientific legacy includes editorship of the finest example of cultural and biophysical landscape history yet achieved anywhere - the Ystad project, published as 'The cultural landscape during 6000 years in Southern Sweden' in 1991. To honour Biörn and to celebrate 50 years of Quaternary research in Lund, the Department organised a meeting on 'Environmental Changes in Fennoscandia during the Late Quaternary', May 28-29, 2000. We thank Biörn for his many contributions and wish him a long, productive and happy retirement. 